\title{
STUDY OF THE STUDENTS' INTEREST IN THE FOOTBALL GAME, MOTIVATION AND DESIRE FOR PRACTICING FOOTBALL
}

\author{
G. Dyakova ${ }^{1}$, T. Dyakov ${ }^{2}$, I. Angelova ${ }^{1}$ \\ ${ }^{1}$ Trakia University, Stara Zagora, Bulgaria \\ ${ }^{2}$ University of Veliko Turnovo, Bulgaria
}

\begin{abstract}
A survey of 225 students in the first and second year of their course of physical education and sports from all disciplines of the Economic Faculty, Faculty of Agriculture and Faculty of Veterinary Medicine at Trakia University, Stara Zagora, including 22 taught in English in the specialty Veterinary Medicine is carried out. The purpose of this study is to examine the interest of students to the football game, motivation and willingness to turn to football in higher school. In order to achieve the above research purposes, there are applied theoretical analysis, questionnaire method, alternative analysis and graphic analysis. In the survey there are included 18 questions in accordance with the directions of interest in this study. The results and analysis indicate that the football game is liked by the students, but this act needs to be complemented by active actions on their part. Receiving positive emotions and improvement of physical fitness is a leading motive for practicing football in higher school. The results give us reasons to conclude that this study reveals an opportunity for innovation in the means and forms of physical education in higher schools.
\end{abstract}

Key words: higher schools, examination, innovation, education

\section{INTRODUCTION}

Physical education and sport in higher education institutions are an integral part of the students' education in the form of mandatory and facultative activities. The process of training in higher education institutions in the discipline of physical education is a complex scientific-theoretical and practical-applied pedagogical problem, implying motivated willingness of the students for active and full participation in it. The two sides of this process play a decisive role in success - the pedagogical function of the teacher and the student's learning activity on the other, in other words - his motivation.The optimization of the educational process in physical education has a theoretical-methodological and applied character requiring periodic updating of the curricula and programs, incl. accompanying and exploring the interest of students to various motor activities and sports. For the full realization of the physical education teaching in the higher schools (HEIs), there is a need for appropriate actions to improve the technical skills, physical qualities, psychological abilities and tactical and theoretical knowledge already acquired in the previous levels of education (1-6). Periodic updating of the curriculum is a priority for
HSU teachers, which is based on in-depth studies and studies in students.At the Thracian University the activities of the students from the Economic Faculty, Faculty of Agriculture and Faculty of Veterinary Medicine at Trakia University, Stara Zagora are held under a curriculum prepared by the Department of Physical Education and Sport. Her content includes Fitness; Volleyball; Cycling; Basketball; Athletics; Table tennis; Galiletics; Tae-bo and Pilates.

After studying the literature available to us concerning the methodology and organization of physical education in higher schools, we focused on studying the interest of the students towards the growing popularity of recent years and among the girls football.

\section{PURPOSE}

The aim of the present study is to investigate the interest of students in football, their motivation and the desire to practice football in the high school.The following tasks are to be accomplished:

1. Theoretical study of the problem.

2. Preparation of the questionnaire and conducting of the survey 
3. Processing the information provided and analyzing the results obtained.

\section{METHODS}

The study was conducted with 225 students in the first and second courses at the Thracian University - Stara Zagora (Faculty of Economics, Faculty of Agriculture and Veterinary Medicine, trained in the fields of Agricultural Economics, Regional Economics, Business Economics, Veterinary Medicine Medicine, Animal Breeding, Agronomy, Fisheries and Aquaculture, Ecology and Environmental Protection, and Agricultural Engineering), including 22 students in English, specializing in Veterinary Medicine.When developing the study, the following tools were applied:

- Alternative analysis. The relative share of the response was calculated in relation to the total number of respondents

- Survey method. In order to study the motivation of the students to engage in exercise activities, a questionnaire of 18 questions was held. When compiling the survey, the basic requirements for short, clear and accessible formulations of questions, avoidance of ambiguous questions, and such questions that point to a specific answer are met.

- Graphic analysis and

- Comparative analysis of relative shares.The study was conducted during the summer semester of 2016/2017.

The questionnaire includes 18 questions in line with the areas of interest in this study.

\section{RESULTS AND DISCUSSION}

The average age of the subjects studied is 19.8 years. Figures 1 through 18 show a graphical distribution of the students' answers to the questionnaire questions. The conduct of the questionnaire begins with the question "Do you like football?". This is a basic question, and answers give a very high relative share 72.9 for students who have indicated they like football (Figure 1). The purpose of the second question is to give more clarification on the first question and has a specifying character, If it is stated that they like football, the people surveyed are expected to answer why they like it. Of those students who like football with the largest relative share - 63.1 say they like it because it brings them positive emotions, $7 \%$ because they are interested in it, and $2.8 \%$ because it is the most popular game (Figure 2). The results show that the emotional motif leads to a positive attitude towards the football game. On the third question "Do you watch football matches?" The positive and negative answers differ by 4 relative shares. Of those surveyed, $48 \%$ said they were watching football matches. Here is a fact that provokes reflection. Despite the high percentage of positive respondents who liked football (72.9\%), only $48 \%$ saw football matches (Figure 3). The question remains, the difference of $24.9 \%$ of people surveyed, why do not they prefer watching football matches? The answers to the fourth question are in Figure 4. It shows that those who watch football matches once a month have the highest relative share of 28 . This answer is logically expected and it is no surprise to us. The "other answer" indicated is $15.6 \%$, and there are answers like "often", "when I have time" "when I'm in the mood," "when playing my favorite team," or "when I'm in a company" To set regularity over time but to reflect positive situations. Once a week soccer matches are seen by $3,1 \%$ of the students, and most often watching soccer - each day is $0,4 \%$. The fifth question involves specifying at what level of sporting competitions the interest of the students in the observation of football matches is reduced. The highest relative share is in the observing meetings of international championships - 28.4, the lowest - from the Bulgarian Championship 6.2, which shows the preferences for certain sporting events (Figure 5). In view of the level of the Bulgarian championship, the results obtained are not a surprise for us.It is clear from the answer to the sixth question that a very small proportion of the students $(3.1 \%)$ participated in an organized training process under coaching leadership (Figure 6). The positive thing here is that despite the small relative share, there are still students who have practiced football. The results of the seventh question are shown in Figure 7. It shows that there is not one student who has trained over the past year. The same percentage of trainees have been "over the last five years" and trained for "more than five years" - 1.35. "Still training" was answered by $0.4 \%$ of the people surveyed. By eighth question, it was found that those who trained under coaching and participated in football competitions - 3.1\% (Figure 8). The answers to the ninth question (Figure 9) specify the rankings of the competitions in which the students who said they had practiced football participated. With an equal share of 1.33 participants participated in "school competitions" and "in Bulgarian regional competitions". In international competitions, $0.4 \%$ participated. The tenth question seeks to obtain information on how much of the people surveyed played football in other words - have ever participated in a football game. The results show that approximately half of them - 
$49.3 \%$ - were involved in such occupation (Figure 10). From Figure 11, we get information about when the people surveyed played football. The highest relative share was played over the past five years - 36. This is the answer to the question determining the longest period mentioned in this survey. Within the last 5 years, they played $8.9 \%$, and in the last year $4.4 \%$ of the surveyed. Interestingly, the answers to the next question (Figure 12) Here we can make a guess. From the answers to the previous question, it appears that $36 \%$ of the students have played football, and from the answers to the twelfth question, it is clear that $35.6 \%$ of the students did this at school. We assume that the relative relative share refers to the same contingent of the surveyed individuals. During holidays, football played $7.1 \%$ and $6.6 \%$ gave another answer. The next question, "Do you have the knowledge of the football game technique?" Provides answers that are particularly relevant to the survey (Figure 13). With the largest relative share responded "rather not" - 53.8, negative response indicated $17.7 \%$, ie. according to a total of $71.5 \%$ of the surveyed there is a lack or lack of knowledge about the technique of the football game. Relatively smaller share is the students who think they have such knowledge - $17.7 \%$ responded with "rather yes" and $10.8 \%$ - with "yes". These results, which show a lack of knowledge, could justify the possible inclusion of a student's footage in the Physical Education curriculum in order to enrich the educational work with them. Figure $\mathbf{1 4}$ reflects student selfassessment for football rule-of-play. The results of this and thirteenth issue are relative in relative shares. Of those surveyed, $68 \%$ said they had no knowledge of the rules in the football game (with "rather no" responding $45.8 \%$ and no "22.2\%). A definite desire, in the curriculum of Physical Education to include football, shows $38.2 \%$ of the respondents (Figure 15). Considering that $72.9 \%$ of the surveyed people say that they like football, the first question from the poll (Figure 1), we have reason to assume that respondents with "I can not judge" - $34.7 \%$, Would provide credit for confidence in deciding to include this sport in the curriculum, and in the students, the competences of the faculty of the Department of Physical Education and Sport. Reluctance to include football in the curriculum is $27.1 \%$. The challenge in upcoming activity is the work with this contingent in particular. On the sixteenth question, "Please answer what do you think will contribute to the inclusion of football in the university curriculum?", More than one answer is allowed. The highest relative share is that the football game will bring positive emotions - 86.4. Nearly this result $-81.3 \%$ believe it will improve their physical fitness. Knowledge of the elements and rules of the game are expected to gain $28.1 \%$. They can not judge what contribution they will make to $11,5 \%$ football. With an insignificant relative share -2.2 are the students, according to whom "nothing will contribute" any participation in football activities (Figure 16). Getting positive emotions and improving physical fitness is a leading motivation for the desire to practice football in the high school. The seventeenth question seeks to develop students' preferences, their interest in various motor activities and sport, already included in the curriculum of Physical Education and Sports at the Higher School. This study will help deciding to eventually drop some of the unattractive motor activity and sport and replace them with female football. In this sense, interest is represented by the most unattractive Tae-bo $2.4 \%$ and Pilates $1.2 \%$ (Figure 17). Removing them would make it possible to include student activities in the curriculum. The latter question seeks to explore the student's view of the number of hours for which football is included in the curriculum (Figure 18). It is not surprising for us the very large relative share -84 of the interviewed students who can not judge this. It is obvious that a significant part of the students do not engage in this answer and reasonably provide the decision of the competent persons (the teachers) in this regard. Few more than one tenth $-11.1 \%$ of the surveyed people expressed the opinion that football must be included with 30 hours of workload.

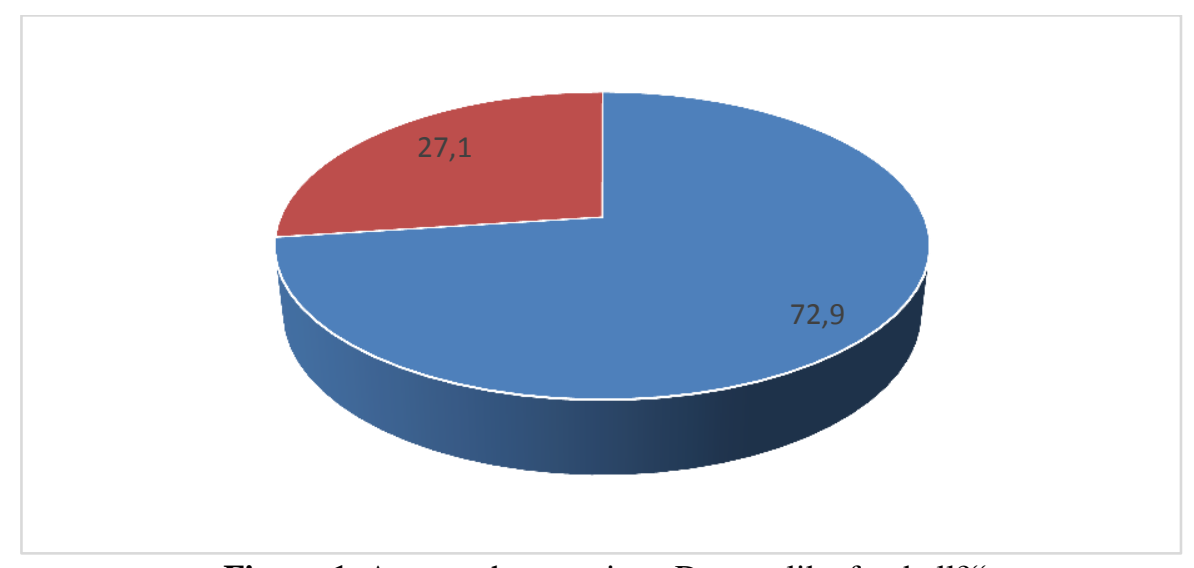

Figure 1. Answer the question „Do you like football?“ 


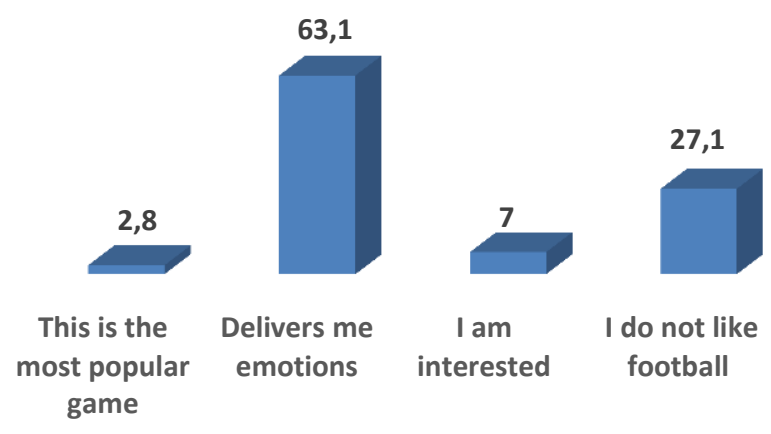

Figure 2. Answer the question „If you answered "yes, I like football" to question №1, please answer why you like football?"“

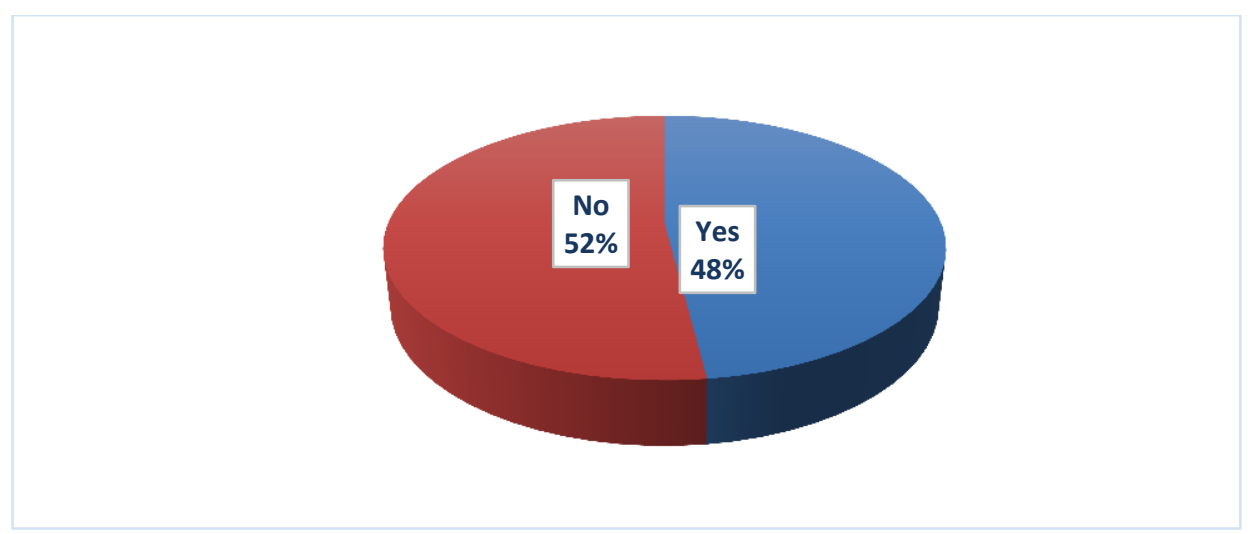

Figure 3. Answer the question „Watch soccer matches?

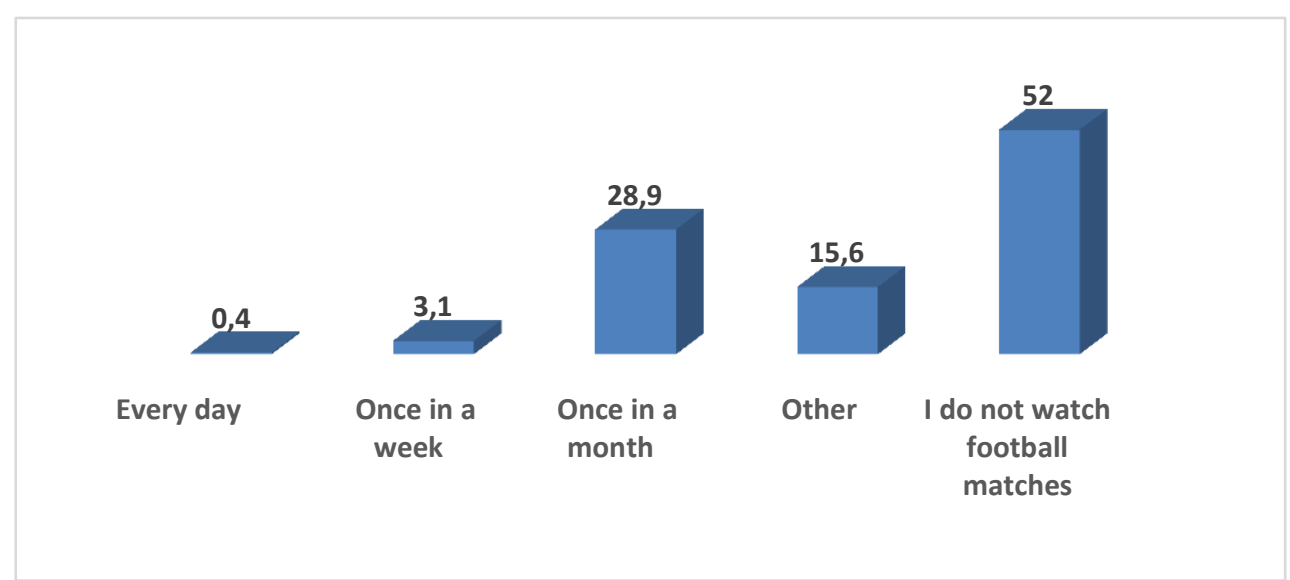

Figure 4. Answer the question „If you watch football, please answer how often do you watch football games?“

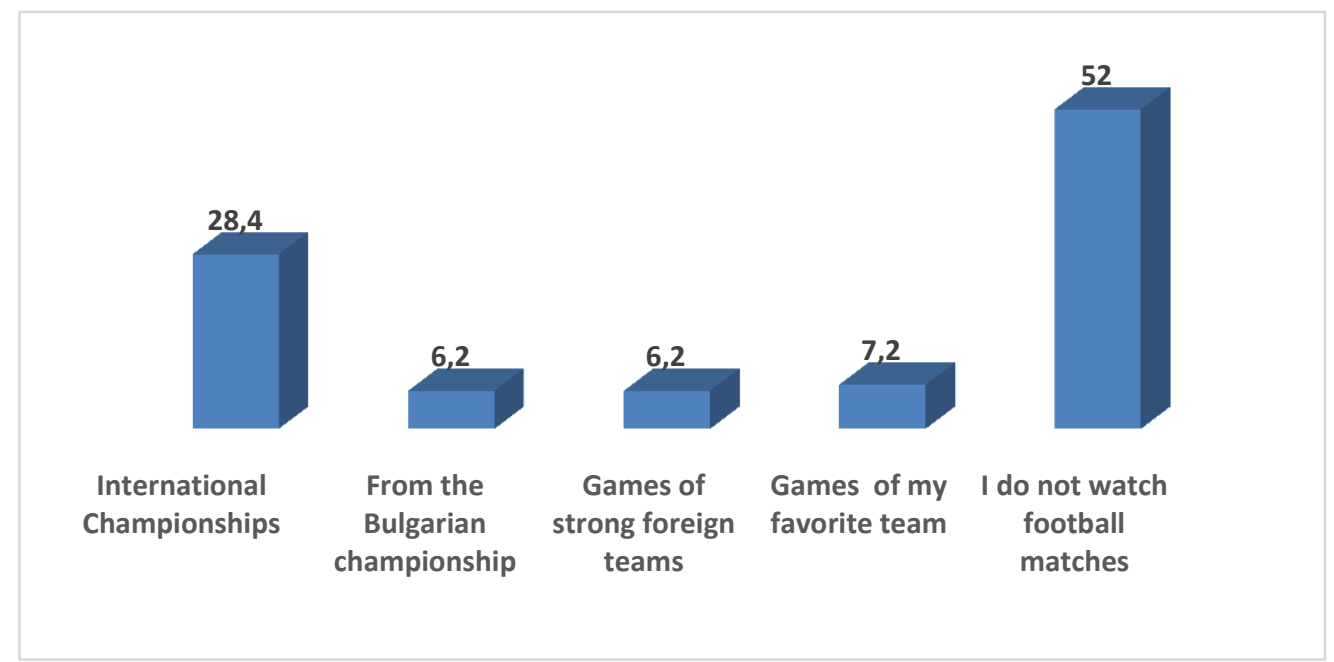

Figure 5. Answer the question „If you watch football, please answer what games you prefer to watch?“ 
3,1

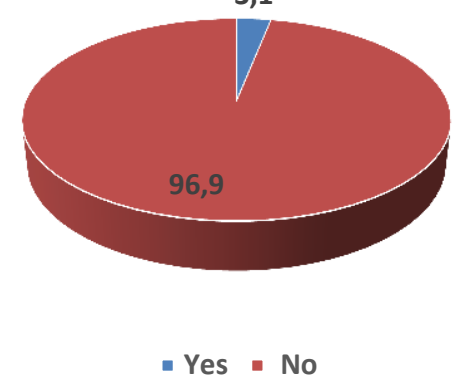

Figure 6. Answer the question „Have you ever train soccer (in organized training process under the coaching guidance )?"

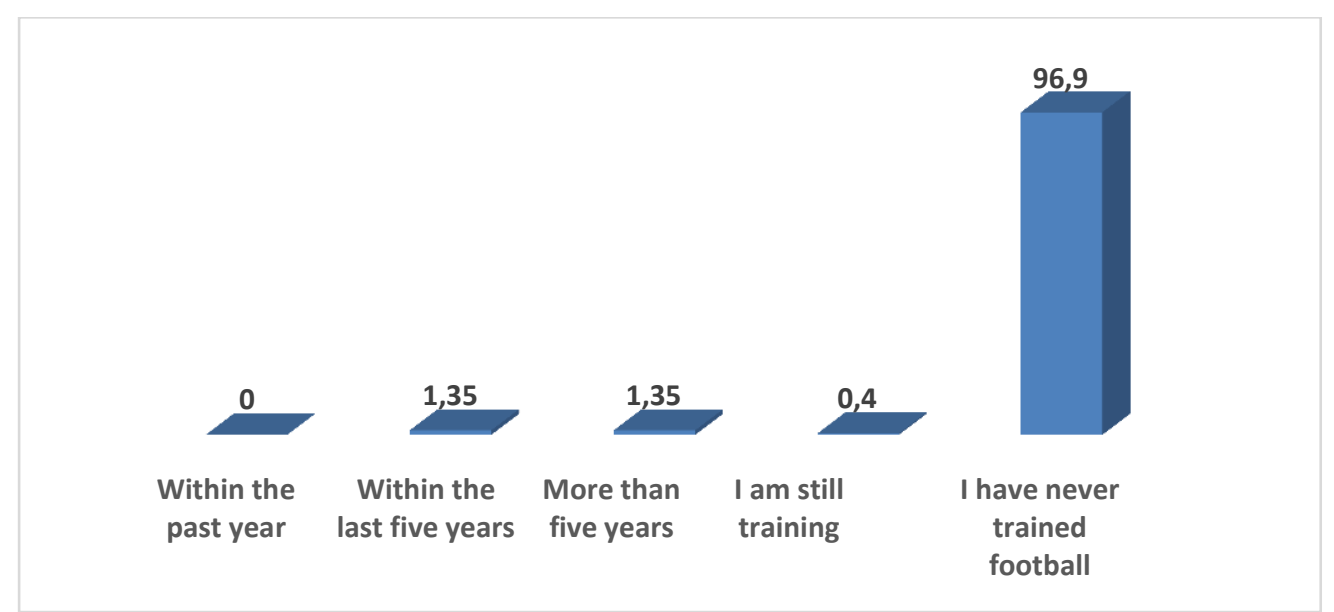

Figure 7. Answer the question „If you trained soccer, please answer when you have trained football?“

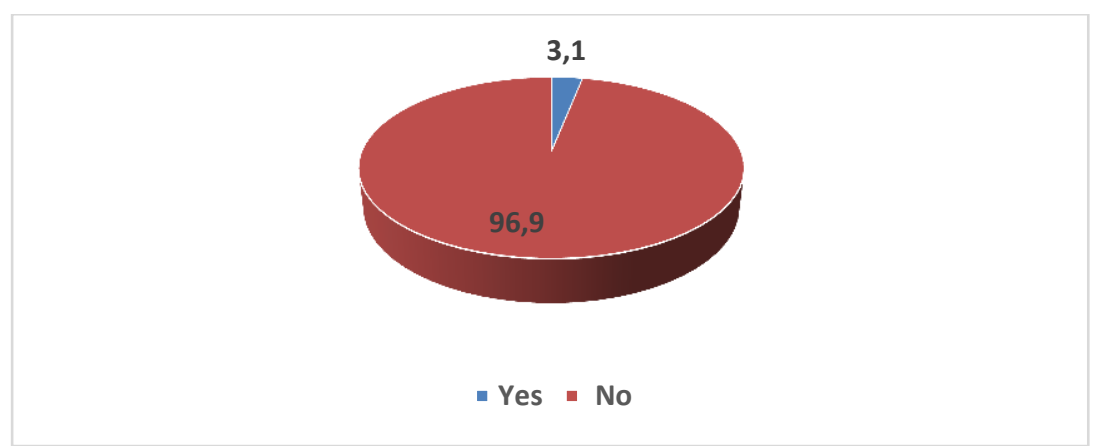

Figure 8. Answer the question „If you have trained soccer, please answer have you ever participated in any competitions?“

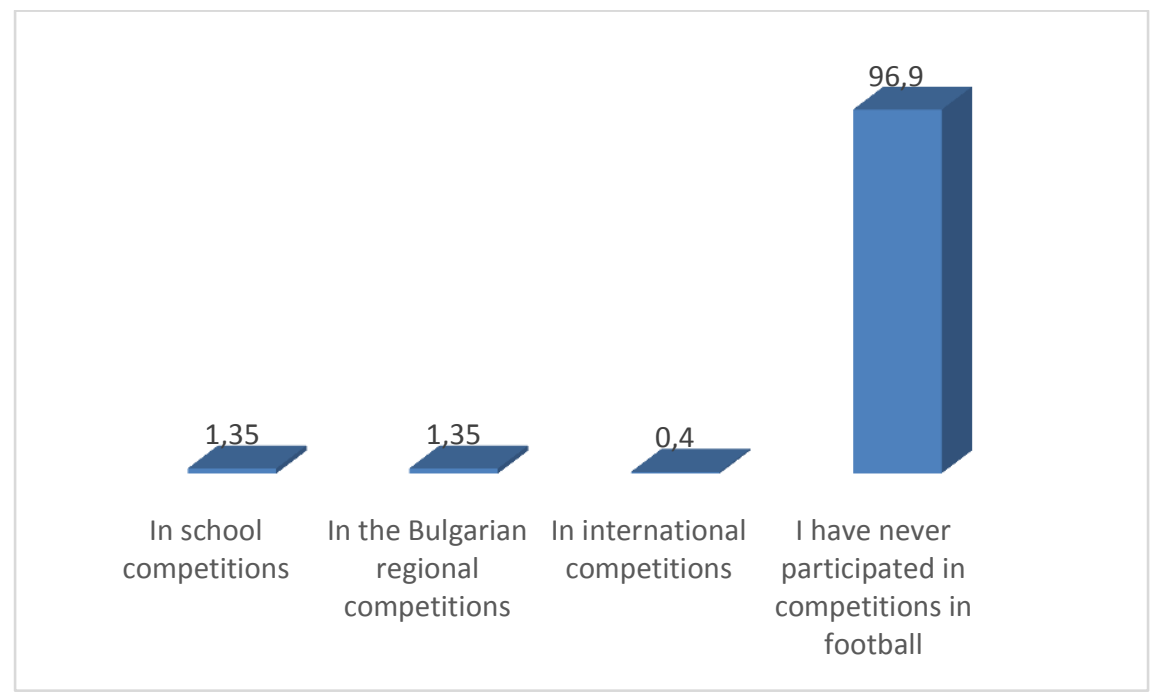

Figure 9. Answer the question „If you have participated in competitions in football, answer in what events you participated?“" 


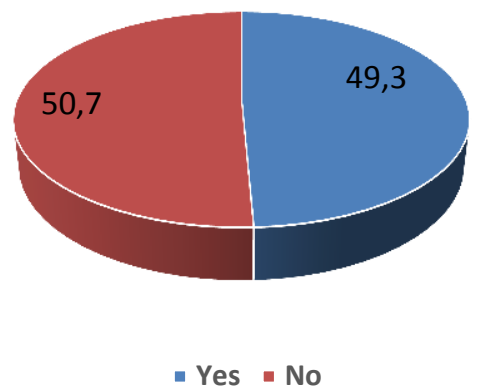

Figure 10. Answer the question „Have you played football ever?“

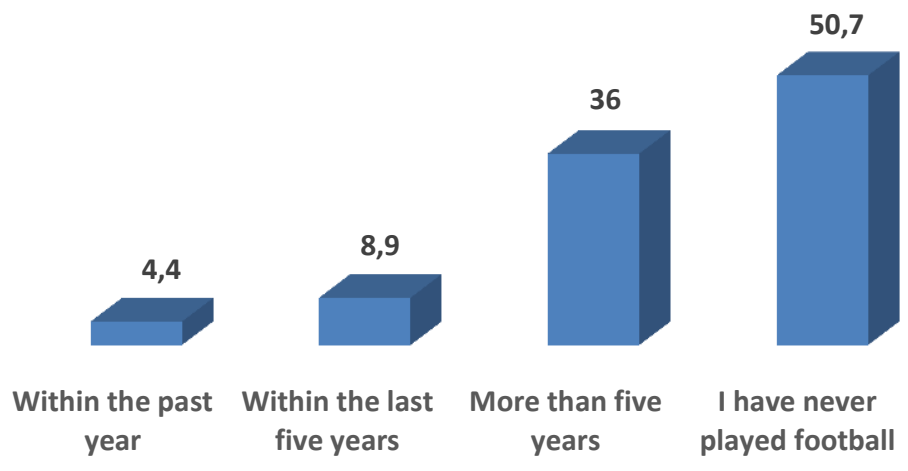

Figure 11. Answer the question „If you answered "yes" to question "Have you played football ever?”, please answer when you played football?"

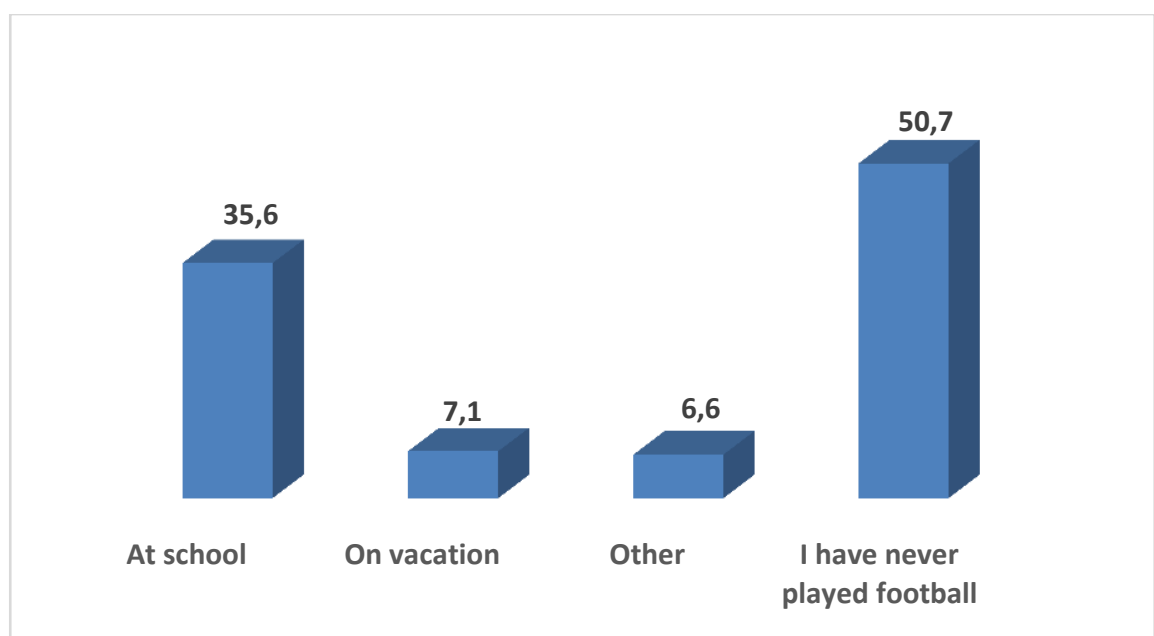

Figure 12. Answer the question „If you played football, where it happened?“

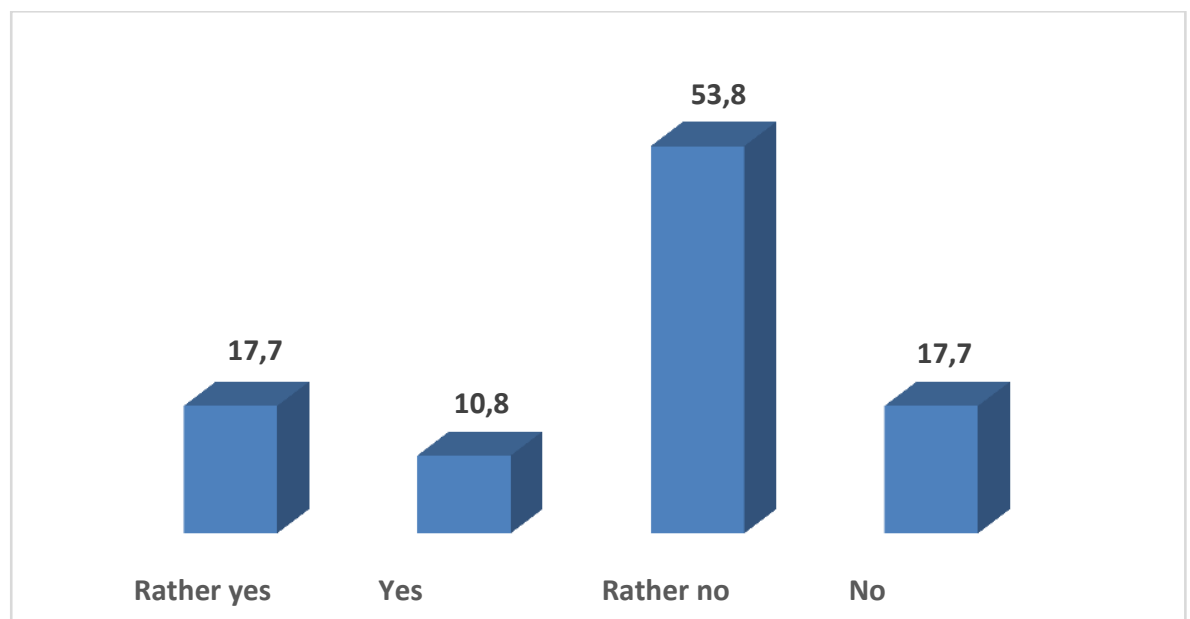

Figure 13. Answer the question „Do you have knowledge about the technique of the football game?“ 


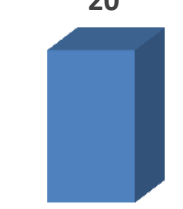

Rather yes

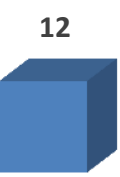

Yes

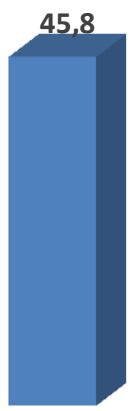

Rather no

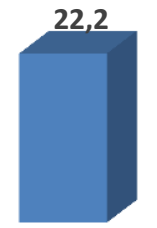

No

Figure 14. Answer the question „Do you have knowledge of the rules in the football game?“

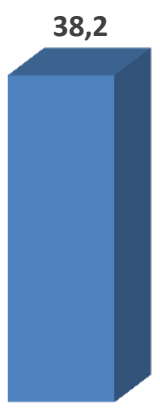

Yes

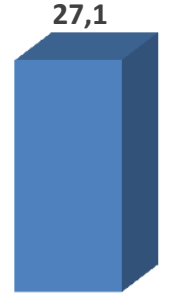

No

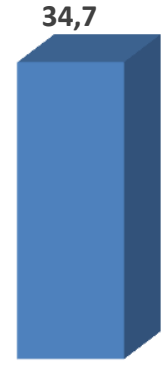

Do not know

Figure 15. Answer the question „Do you want in the curriculum at the university to be added football?“

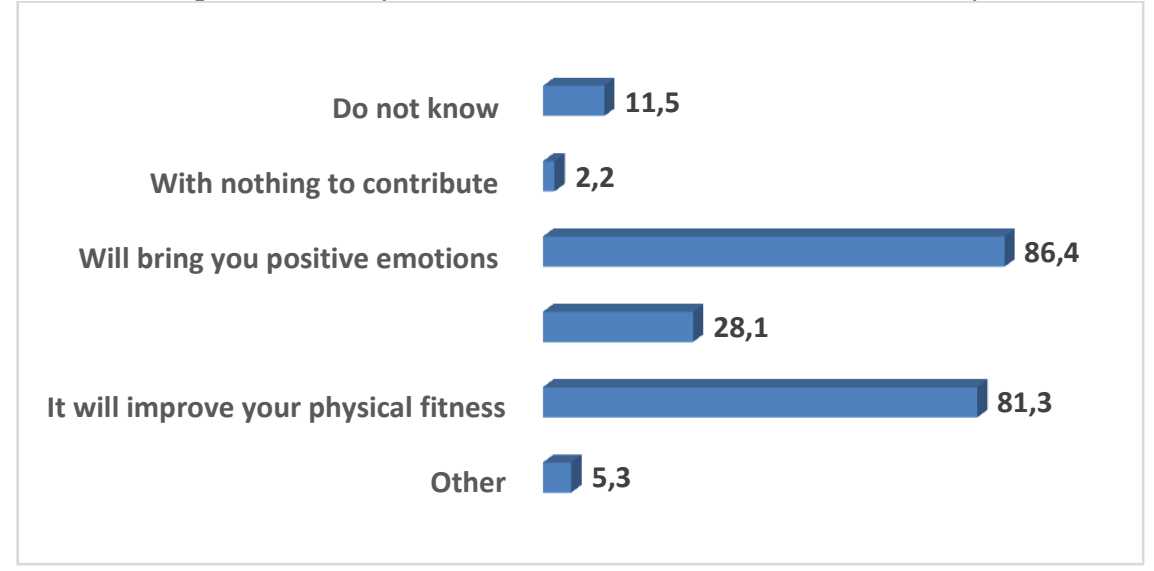

Figure 16. Answer the question „Please answer with what you think will contribute inclusion of football in the curriculum at the university? You can answer more than once."

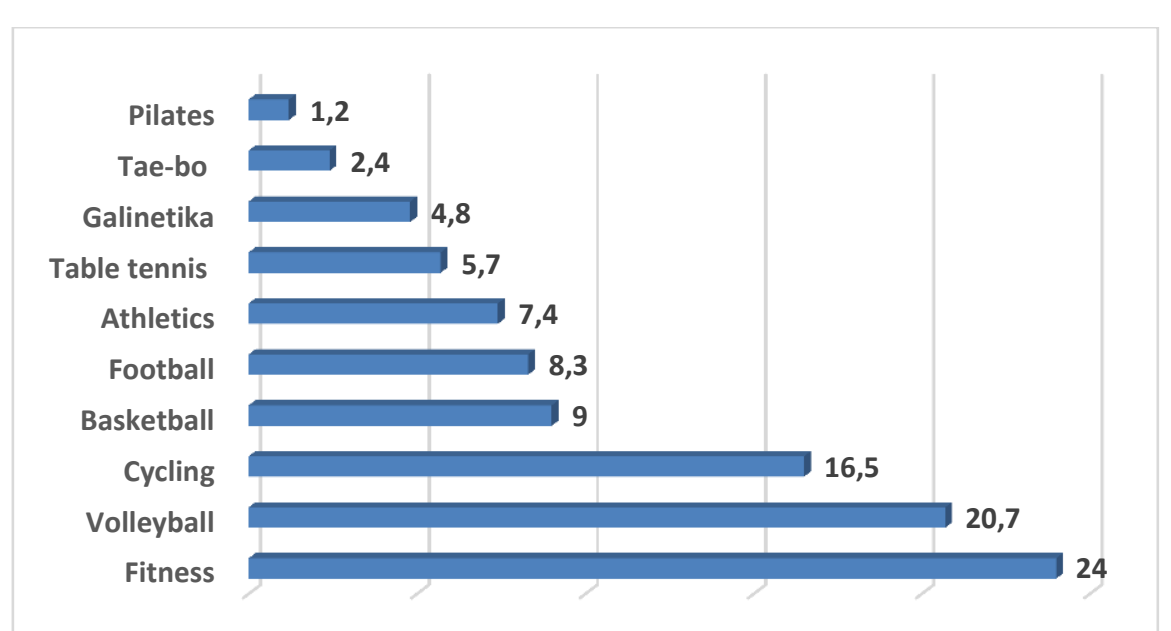

Figure 17. Answer the question „Please according to your interests, would you number from 1 to 10 following physical activity and sport?" 


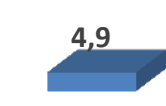

20 hours

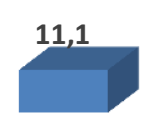

30 hours

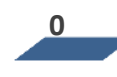

Other

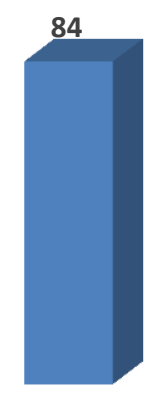

Do not know

Figure 18. Answer the question In your opinion, how many hours to include football in the curriculum?

\section{CONCLUSIONS}

In conclusion, we can draw the following conclusions:

1. The results and their analysis indicate that the football game is liked by the students, but this act needs to be met with active actions on their part.

2. Getting positive emotions and improving physical fitness is a leading motivation for practicing football in the high school.

3. A significant part of the students have no knowledge of the technique and rules of the football game.

4. The obtained results give us grounds to conclude that the conducted research reveals an opportunity for innovation in the means and forms of education in Physical Education at the higher school.

\section{RECOMMENDATIONS}

Exploring interest in football, motivation, and desire to do high school football at students will have an applied character if the following recommendations are met:

1. In connection with the optimization of the curriculum of the FBI, to develop a section on female football in it.

2. Experimentally introduce a one-year trial with the innovative form of training.

\section{REFERENCES}

1. Doncheva, M. Volleyball at a school on the threshold of the new millennium. Vol. 1, Varna, 2001.

2. Dyakova, D. Exploring the interests of students to various content in physical education. C \& H, cf. Pc. 1, S., 2005.

3. Yordanova, N. Analysis of the Educational Content of the Subject Physical Education and Sport. C \& H, C., 2007.

4. International Charter for Physical Education and Sport (UNESCO). Legislative documents in the field of sport. Ministry of Youth and Sports. International charters and conventions in the field of sport. S., 2004.

5. Chekoeva, I. Medical students' personal motivation for physical Activity during education. VI International Language Conference "Productive Language Skills for Academic Purposes", 7-8 October, Sb., 386-390, ISBN: 978-954-9685-64-0, Varna, 2011.

6. Petrov, L., D. Dimova, P. Eneva. Physical training in lessons of different character. International Scientific Congress "Sports, stress, adaptation" - NSA, S., 1999. 